\title{
Correction to: Differential Effectiveness of an Inferential Reading Comprehension Intervention for Struggling Middle School Readers in Relation to Mind-wandering, Anxiety, Mindset, and English Learner Status
}

\author{
Amanda Martinez-Lincoln ${ }^{1,2} \cdot$ Marcia A. Barnes ${ }^{1} \cdot$ Nathan H. Clemens ${ }^{2}$ \\ Published online: 16 February 2021 \\ (C) The International Dyslexia Association 2021
}

\section{Correction to: Annals of Dyslexia \\ https://doi.org/10.1007/s11881-020-00209-7}

The original version of this article unfortunately contained a mistake in the article title. The correct title is "Differential Effectiveness of an Inferential Reading Comprehension Intervention for Struggling Middle School Readers in Relation to Mind-wandering, Anxiety, Mindset, and English Learner Status" and it is corrected with this erratum/correction.

The online version of the original article can be found at https://doi.org/10.1007/s11881-020-00209-7

Amanda Martinez-Lincoln

Amanda.Martinez-Lincoln@Vanderbilt.Edu

1 Present address: Department of Special Education, Peabody College at Vanderbilt University, Nashville, TN 37203, USA

2 Department of Special Education, The University of Texas at Austin, Austin, TX, USA 